\section{Emphysema: time to say farewell to therapeutic nihilism}

\author{
Zaid Zoumot, Simon Jordan, Nicholas S Hopkinson
}

It is an interesting time for the management of emphysema. In this condition, destruction of lung parenchyma associated with reduced elastic recoil and dynamic airways closure produce gas trapping and increased operating lung volumes, leading to breathlessness and exercise limitation. It has historically been defined as an irreversible process, which has led to a degree of therapeutic nihilism. One manifestation of this has been the curious neglect of lung volume reduction surgery (LVRS). Clinical guidelines, ${ }^{1}$ reflecting trial evidence, ${ }^{2}$ recommend consideration of LVRS in selected patients with upper lobe predominant emphysema and poor exercise capacity, the phenotype where surgery has been shown to produce a survival benefit. Modern surgical techniques, unilateral treatment and improved postoperative care and patient selection mean that LVRS is also associated with lower morbidity and mortality than data published at the turn of the century had suggested, ${ }^{3} 4$ with one recent case series reporting zero 90 -day mortality following unilateral surgery. ${ }^{5}$

Nevertheless, little effort seems to be going into identifying this patient population and LVRS remains vastly underused with just 90 procedures taking place in the UK in 2010-2011. A partial explanation for this may be found in a recent survey of British Thoracic Society members that revealed that a significant proportion overestimated the morbidity and mortality associated with LVRS. ${ }^{6}$ Only $30 \%$ had access to a dedicated chronic obstructive pulmonary disease (COPD) multidisciplinary meeting to review patients, and there was no consensus as to the correct strategy to adopt to identify appropriate patients.

Over the last decade, bronchoscopic approaches for lung volume reduction in emphysema have proliferated. These include one-way endobronchial valves to

NIHR Respiratory Biomedical Research Unit, Royal Brompton and Harefield NHS Foundation Trust and Imperial College London, London, UK

Correspondence to Dr Nicholas Hopkinson, NIHR Respiratory Biomedical Research Unit, Royal Brompton and Harefield NHS Foundation Trust and Imperial College London, Royal Brompton Hospital, Fulham Rd, London SW3 6NP, UK; n.hopkinson@ic.ac.uk induce lobar collapse, ${ }^{7-10}$ airway bypass approaches to create low-resistance extraanatomical pathways that allow trapped gas to escape, ${ }^{11} 12$ lung volume reduction coils (LVRC) that re-tension the lung preventing dynamic airway collapse ${ }^{13}$ and techniques intended to reduce lung volumes by scarring either through bronchial thermal vapour ablation ('steam') ${ }^{14}$ or the use of biological agents. ${ }^{15} 16$ These approaches offer the potential to achieve lung volume reduction, improving symptoms and even prolonging survival ${ }^{8}$ while avoiding the problems inherent in an invasive surgical intervention. However, for each approach issues around the magnitude and duration of effect, optimum patient selection, safety profile and cost need to be addressed through properly conducted clinical trials with robust endpoints.

Deslee and colleagues present 6-month and 12-month data from a multicentre, single-arm study of staged, bilateral LVRC treatment in patients with severe emphysema. ${ }^{17}$ They report improvements in St George's Respiratory Questionnaire (SGRQ) scores of $-11.1 \pm 13.3$ points 12 months following therapy as compared with baseline, with persistent benefits in 6 minute walking distance (6MWD), forced expiratory flow in the 1 st second $\left(\mathrm{FEV}_{1}\right)$ and residual volume (RV) exceeding accepted minimal clinically important differences. These data are encouraging and add to existing data from short-term controlled trials, ${ }^{13}$ but the limitations of this study merit some consideration when considering the general issues for bronchoscopic therapies outlined above. It was uncontrolled and unblinded, with only roughly half the cohort followed up beyond 6 months and the primary outcome was a quality of life score. This is questionable in a single-arm study without a sham procedure, given the powerful placebo effect seen with this sort of intervention. Nevertheless, the sustained improvement in lung volumes seems to indicate a persistent physiological effect. Longer-term follow-up in randomised controlled studies will be needed to be able to comment definitively on sustained benefits of LVRC. The RENEW trial (clinicaltrials.gov NCT01608490), which is currently underway with a primary endpoint of 6MWD 12 months post-recruitment will address this.
The authors do not clarify what the distribution of recruitment among the 11 participating centres was or their prior experience with the technique. Two patients recruited for bilateral coil treatment were then thought to be unsuitable for contralateral treatment on a 'second look' at their imaging. In addition, the trial was meant to enrol only patients with heterogeneous disease, yet 13 and 17 of 33 patients reaching 12 months' follow-up were deemed 'homogeneous' on visual and computerised scoring, respectively. The authors propose that homogeneous emphysema responds to treatment with LVRC to a similar extent to heterogeneous disease, but this must be considered hypothesis generating only and to some extent seems to reflect a failure in the application of the initial protocol. The problem of recruiting patients for lung volume reduction trials who on post hoc analysis do not fulfil entry criteria is not unique to this study. ${ }^{7} 11$

Safety is another key issue. It has been assumed that bronchoscopic lung volume reduction is safer and cheaper than LVRS. Pneumothorax occurred within 30 days in 4 of 155 procedures (3.5\%), with a per patient rate of $11.7 \%(7 / 60)$ during the follow-up period. Pneumothorax following bronchoscopic lung volume reduction procedures can be delayed and can be fatal. This means that as well as formal safety criteria around lung function and exercise capacity a general clinical assessment of the patient's likely ability to cope with this complication needs to be made. In practice, relatively few people judged 'too unwell for LVRS' may be eligible for a bronchoscopic approach. All patients treated as part of this trial had general anaesthesia in an operating theatre, but it should be noted that these procedures can be performed safely in the bronchoscopy suite under sedation. ${ }^{13}$

A review article written a decade ago posed the question 'Endobronchial lung volume reduction, a myth, or a marvel? ${ }^{18}$ The proliferation of techniques and publications mean that these approaches can no longer be considered mythical, but nor any longer are they 'a marvel'. Rather, they must be considered as techniques with a developing evidence base and varying response rates and complications where a case must be made that they represent good value, considered in terms of the resources employed and the health outcomes obtained. The London Respiratory Network has produced a value pyramid for COPD interventions ${ }^{19}$ (figure 1), but it remains to be established where each bronchoscopic approach will sit. LVRS was estimated as costing $\$ 40,000$ per quality adjusted life year (QALY) based on 
Figure 1 The pyramid of value for COPD interventions developed by the London Respiratory Network with The London School of Economics (modified from $^{19}$ ) gives estimates of cost per quality adjusted life year gained. LABA long-acting $\beta 2$ agonist; QALY, quality adjusted life year.

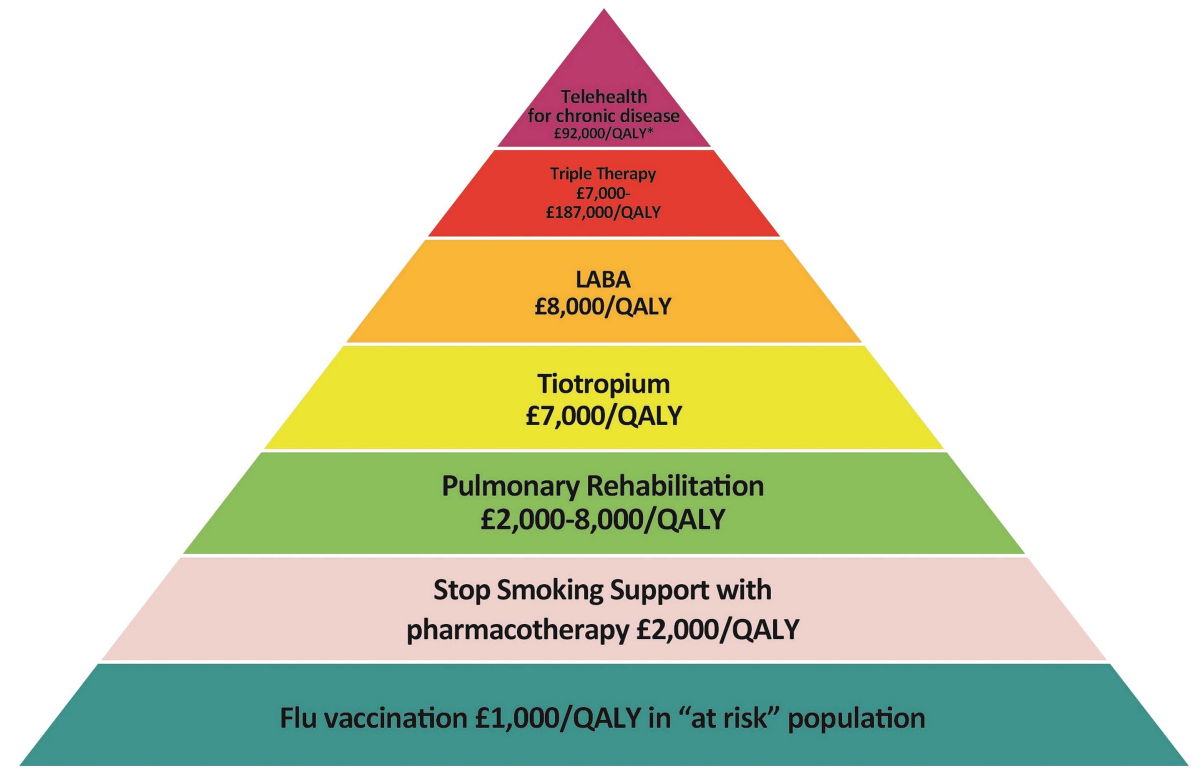

Table 1 Approach to selecting patients with emphysema for a possible lung volume reduction procedure

General criteria when considering a lung volume reduction procedure

- Significantly reduced exercise capacity.

- Lung function impairment with significant hyperinflation.

- Sufficiently well to cope with surgery.

- Prepared to accept some procedural risk (requires clinicians to be able to communicate this accurately).

- There is a 'window of opportunity' for intervention. In 'end-stage' patients, it may be too late to intervene safely.

\begin{tabular}{ll}
\hline Considerations & Criteria \\
\hline Are they too well to consider intervention? & Lung function, exercise capacity, prognosis, Medical Research Council dyspnoea score $<3$ \\
\hline Are they too unwell for intervention to be safe? & Lung function, frailty, exercise capacity $<100 \mathrm{~m}$, oxygen dependence \\
\hline Is treatment optimal? & Smoking cessation, pulmonary rehabilitation, flu vaccination, inhaled and oral medication \\
\hline $\begin{array}{l}\text { Is their lung function likely to rule out a procedure on safety } \\
\text { grounds? }\end{array}$ & All three of FEV ${ }_{1}$, TLco and Kco $<20 \%$ predicted \\
\hline $\begin{array}{l}\text { Do they have comorbidities that limit likely benefit or } \\
\text { increase risk? }\end{array}$ & $\begin{array}{c}\text { For example, pulmonary hypertension, unstable cardiac disease, malignancy, cerebrovascular disease. } \\
\text { Ongoing smoking (possibility of intervention may help to promote quit attempts) }\end{array}$ \\
\hline Have they ever had a CT thorax and if so has it been & Review existing CT's or obtain a CT if a potential candidate as above \\
reported in terms of emphysema pattern?
\end{tabular}

Review $\mathrm{CT}$ and lung function in multi-disciplinary teams including respiratory physician, radiologist, thoracic surgeon

Further investigations including echocardiogram, lung perfusion scan and a formal field exercise test (shuttle walk or 6 minute walk test) may be indicated.

the US National Emphysema Treatment Trial (NETT) ${ }^{20}$ but the likely true figure is considerably lower, given improvements in technique with reduced mortality, morbidity and length of stay. ${ }^{521}$ The cost of LVRCs is at present high with the list price of the devices themselves significantly exceeding the national LVRS tariff in the UK.

As with LVRS, the response rates for bronchoscopic techniques are crucially dependent on appropriate patient selection, with different criteria for different devices. This takes us back to the need to develop an multi-disciplinary team (MDT) approach for emphysema ${ }^{5} 21$ (table 1). Given trial data indicating improved survival, a failure to offer LVRS to appropriate patients with COPD and by extension a failure to make the effort to identify them seems to us to border on negligence. The development of a network of emphysema MDTs should also facilitate the more rapid delivery of trials to investigate the efficacy of experimental treatments and ensure that appropriate criteria are used to select individuals for more established interventions such as endobronchial valves to ensure a high responder rate and the best value for the healthcare system.

Contributors ZZ wrote a first draft of the editorial to which all the authors contributed before approving the final version.

Conflicts of interest NSH runs an advanced COPD clinic where patients are evaluated for lung volume reduction procedures. He has been an investigator in trials of endobronchial valves, airway bypasses and lung volume reduction coils (LVRC). The authors' institution has received reimbursement for trial expenses by PneumRx Inc., the manufacturer of the LVRCs and other bronchoscopic lung volume reduction device manufacturers. ZZ has received travel grants from PneumRx Inc. to present trial data at international conferences. None of the authors have any personal financial interests related to companies producing lung volume reduction products.

Provenance and peer review Commissioned; internally peer reviewed.

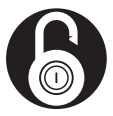

\section{OPEN ACCESS}


Open Access This is an Open Access article distributed in accordance with the Creative Commons Attribution Non Commercial (CC BY-NC 3.0) license, which permits others to distribute, remix, adapt, build upon this work non-commercially, and license their derivative works on different terms, provided the original work is properly cited and the use is non-commercial. See: http:// creativecommons.org/licenses/by-nc/3.0/

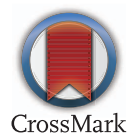

To cite Zoumot Z, Jordan S, Hopkinson NS. Thorax 2014;69:973-975.

Received 2 June 2014

Accepted 4 June 2014

Published Online First 1 July 2014

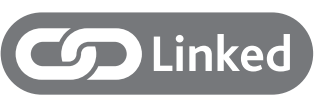

- http://dx.doi.org/10.1136/thoraxjnl-2014-205221

Thorax 2014;69:973-975.

doi:10.1136/thoraxjnl-2014-205667

\section{REFERENCES}

1 National Institute for Clinical Excellence. Management of chronic obstructive pulmonary disease in adults in primary and secondary care (partial update). This guideline partially updates and replaces NICE clinical guideline 12. http://guidance. nice.org.uk/CG101 2010.

2 Criner GJ, Cordova F, Sternberg AL, et al. The National Emphysema Treatment Trial (NETT): part II: lessons learned about lung volume reduction surgery. Am J Respir Crit Care Med 2011;184:881-93.

3 National Emphysema Treatment Trial Research Group. A randomized trial comparing lung-volume-reduction surgery with medical therapy for severe emphysema. N Engl J Med 2003;348:2059-73.

4 Geddes D, Davies M, Koyama H, et al. Effect of lung-volume-reduction surgery in patients with severe emphysema. N Engl J Med 2000;343:239-45.

5 Clark SJ, Zoumot Z, Bamsey O, et al. Surgical approaches for lung volume reduction in emphysema. Clin Med 2014;14:122-7.

6 McNulty W, Jordan S, Hopkinson NS, et al. Attitudes and access to lung volume reduction surgery for COPD: a survey by the British Thoracic Society. BMJ Open Respir Res 2014;1:e000023.

7 Sciurba FC, Ernst A, Herth FJF, et al. A Randomized Study of Endobronchial Valves for Advanced Emphysema. N Engl J Med 2010;363:1233-44.

8 Hopkinson NS, Kemp SV, Toma TP, et al. Atelectasis and survival after bronchoscopic lung volume reduction for COPD. Eur Respir J 2011;37: 1346-51.

9 Hopkinson NS, Toma TP, Hansell DM, et al. Effect of bronchoscopic lung volume reduction on dynamic hyperinflation and exercise in emphysema. Am J Respir Crit Care Med 2005;171:453-60.

10 Davey C, Zoumot Z, Jordan S, et al. Bronchoscopic lung volume reduction with endobronchial valves for patients with heterogeneous emphysema and intact interlobar fissures (The BeLieVeR-HIFi trial): study design and rationale. Thorax Published Online First. doi: 10.1136/thoraxjn-2014-205127

11 Shah PL, Slebos DJ, Cardoso PFG, et al. Bronchoscopic lung-volume reduction with Exhale airway stents for emphysema (EASE trial): randomised, sham-controlled, multicentre trial. Lancet 2011;378:997-1005.
12 Moore AJ, Cetti E, Haj-Yahia S, et al. Unilateral extrapulmonary airway bypass in advanced emphysema. Ann Thorac Surg 2010;89:899-906. e892.

13 Shah PL, Zoumot Z, Singh S, et al. Endobronchial coils for the treatment of severe emphysema with hyperinflation (RESET): a randomised controlled trial. Lancet Respir Med 2013;1:233-40.

14 Gompelmann D, Heussel CP, Eberhardt R, et al. Efficacy of Bronchoscopic thermal vapor ablation and lobar fissure completeness in patients with heterogeneous emphysema. Respiration 2012:83:400-6.

15 Herth FJ, Gompelmann D, Stanzel F, et al. Treatment of advanced emphysema with emphysematous lung sealant (AeriSeal(R)). Respiration 2011;82: 36-45.

16 Zoumot Z, Kemp SV, Caneja C, et al. Bronchoscopic intrabullous autologous blood instillation: a novel approach for the treatment of Giant Bullae. Ann Thorac Surg 2013;96:1488-91.

17 Deslee $\mathrm{G}$, Klooster $\mathrm{K}$, Hetzel $\mathrm{M}$, et al. Lung volume reduction coil treatment for patients with severe emphysema: a European multicentre trial. Thorax 2014;69:980-6.

18 Toma TP, Hopkinson NS, Polkey Ml, et al. Endobronchial volume reduction: a myth or a marvel? Semin Respir Crit Care Med 2004;25:399-404.

19 British Thoracic Society. IMPRESS Guide to the relative value of COPD interventions. British Thoracic Society Reports, 2012.

20 Ramsey SD, Sullivan SD, Kaplan RM. Costeffectiveness of lung volume reduction surgery. Proc Am Thorac Soc 2008;5:406-11.

21 Rathinam S, Oey I, Steiner M, et al. The role of the emphysema multidisciplinary team in a successful lung volume reduction surgery programme. Eur $J$ Cardiothorac Surg Published Online First: 24 Apr 2014. doi:10.1093/ejcts/ezu129 